Canadian

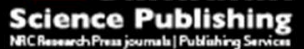

Canadian Journal of Civil Engineering Revue canadienne de génie civil

\title{
Stiffness model for gypsum wallboard-to-wood joints
}

\begin{tabular}{|r|l|}
\hline Journal: & Canadian Journal of Civil Engineering \\
\hline Manuscript ID & cjce-2016-0334.R2 \\
\hline Manuscript Type: & Article \\
\hline Date Submitted by the Author: & 04-Jan-2017 \\
\hline Complete List of Authors: & $\begin{array}{l}\text { Lafontaine, Alexandre; University of Ottawa } \\
\text { Doudak, Ghasan; University of Ottawa }\end{array}$ \\
\hline Keyword: & Gypsum wallboard, light frame wood shearwalls, stiffness \\
\hline \multicolumn{2}{|l}{} \\
\hline
\end{tabular}

SCHOLARONE ${ }^{\text {M }}$

Manuscripts 
Stiffness model for gypsum wallboard-to-wood joints

\author{
Alex Lafontaine ${ }^{1}$; Ghasan Doudak, M. ASCE ${ }^{2}$ \\ 1 alexandrelafon10@gmail.com 22 gdoudak@uottawa.ca
}




\begin{abstract}
:
Joints simulating typical connections of GWB sheathed walls were subjected to reversed cyclic loading. Three different empirical models were analyzed for the purpose of determining the most appropriate fastener slip equation. The power model was used to develop the fastener slip equations, for nails and screws, as a function of GWB density and fastener diameter. The accuracy of the developed fastener slip model is validated against full-scale shear wall tests. The predictive models seem to be able to replicate the wall behaviour with reasonable accuracy until ultimate capacity. The results show a reasonable agreement between the model prediction and those obtained from the shear wall tests. The model perdition of for shear walls constructed with low fastener spacing is less accurate. This result was expected since the small fastener spacing violate the minimum spacing requirements in the design standard (CSA 2014) and caused a brittle failure.
\end{abstract}

Key words: Gypsum wallboards, light frame wood shear walls, stiffness 


\section{INTRODUCTION}

Gypsum wallboard (GWB) is the technical product name referring to a board composed of gypsum core and paper facing; a product commonly referred to as drywall. It is one of the primary building materials used in the construction of walls, ceilings, and partitions, and is typically manufactured to meet the requirements in the ASTM 1396: Standard Specification for Gypsum Board (ASTM 2013a).

GWB can occasionally be relied upon to resist lateral loads, such as those caused by wind or earthquakes, by using it as sheathing material in shear walls. Light frame wood shear walls typically consist of sheathing panels which are fastened to the timber framing. The most common framing consists of spaced wall studs secured by top and bottom plates. Shear walls can be sheathed with panels of plywood, oriented strand board (OSB), or gypsum wallboard (GWB). When a shear wall is loaded in its plane, the joint between the sheathing and framing is loaded in shear. Deformation in a shear wall occurs in the fastener slip, compression and bending of framing members, in-plane shear deformation of sheathing panels, and rigid-body rotation of the wall due to elongation in the hold-down. The fasteners between the sheathing and the framing elements significantly contribute to the overall wall deformation and establishing the load-slip behaviour of various fasteners using in shear wall construction is very important in order to describe their behaviour adequately.

Equation (1) is used to obtain the static deflection at the top of a shear wall segment with woodbased panels used as sheathing (CSA 2014).

$$
\Delta s=\frac{2 v_{s} H_{s}^{3}}{3 E A L_{w}}+\frac{v_{s} H_{s}}{B_{v}}+0.0025 H_{s} e_{n}+\frac{H_{s}}{L_{w}} \Delta_{a}
$$


where $v_{S}$ is the applied shear force at the top of the wall per unit length $(\mathrm{N} / \mathrm{mm}), H_{S}$ is the height of the shear wall $(\mathrm{mm}), B_{v}$ is the Shear-through-thickness rigidity of sheathing $(\mathrm{N} / \mathrm{mm}) . E$ is the modulus of elasticity of end studs (MPa), $A$ is the cross-sectional area of end studs $\left(\mathrm{mm}^{2}\right), L_{w}$ is the length of shear wall $(\mathrm{mm}), \Delta_{a}$ is the total vertical elongation of the wall anchorage system (mm), and $e_{n}$ is the fastener slip (mm).

The fastener slip will be the focus of the current study. It is particularly important to be able to describe the initial behaviour of any fastener used in light frame wood shear walls since this component is notoriously difficult to estimate due to the non-linear behaviour of the joint.

Knowledge about the stiffness of wood shear walls is crucial for the purpose of load distribution, building period estimation and drift calculations. In typical light-frame wall construction the GWB panels are fastened directly to wall elements and can therefore have a significant influence on the overall response of wood frame structures. Underestimating the stiffness of the shear walls, by omitting the contribution of GWB, can lead to an overestimation of the building period, which in turn underestimates the base shear. Currently, no suitably calibrated method is available to estimate the in-plane stiffness of walls with GWB, whether the GWB panels are intentionally considered to contribute to the strength of the lateral load resisting system or simply used as finishing material. The Canadian and American wood design codes (CSA 2014; NDS 2012) currently have provisions to determine the deflection of shear walls sheathed with wood-based panels (plywood and OSB).

There have been numerous tests performed on full-scale shear walls sheathed with wood-based panels. Relatively few tests have been conducted on GWB sheathed shear walls, but the amount has been substantial enough to provide information on failure modes, ductility and peak strength for different specimen configurations (Wolf 1983; Zacher and Gray 1985; Oliva 1990; 
Karacabeyli and Ceccotti 1996; McMullin and Merrick 2002; Dolan 1992; Seaders et al. 2009; Memari and Solnosky 2014; Chen et al. 2016). Most of the tests provide results on shear wall capacity and stiffness but do not propose any stiffness models to estimate shear wall stiffness.

The provisions to determine the deflection of GWB sheathed shear walls available in design standards are limited to nail joints and are rudimentary compared to those available for shear walls with wood-based panels. The 2014 edition of the design standard (CSA 2014) was the first edition to introduce provisions related to slip of nail fasteners when GWB panels are used. The standard stipulates that the joint deformation can be taken as $0.76 \mathrm{~mm}$. This provision was adopted from the American design standard (NDS 2012), however it has obvious limitations, as the value of the displacement is constant and independent of the joint configuration and the load level. This constant value for the fastener slip component of the shear wall deflection equation, results in a linear response and an non conservative approach to determining stiffness at relatively higher loads. Furthermore, there is currently no suitably calibrated model for the GWB sheathed shear walls that are fastened with screws; the most common fastener type for such joints. The current study aims to develop a specific design expression to describe the initial stiffness of GWB-to-wood joints using nail or screw fasteners. The expression could be used by designers to, for example, estimate the deflection of light frame shear walls, where GWB is used as part of the lateral load resisting system. When future considerations to include joint slip in design of connections, the current work can be used for wood members with GWB as side plate.

The load-deflection response of laterally loaded nail joints is non-linear and efforts have been made to provide a model capable of describing this behaviour (Mack 1966; Foschi 1974; Foschi 1977; McLain 1975; William and McCutcheon 1985; Wang 2009). The exponential model was developed as part of a study by Foschi (1974) and it was further compared to typical connection 
in a later research study (Foschi 1977). The advantage of this model is that it utilizes material characteristics as equation inputs as opposed to arbitrary curve fitting parameters. A downside is the relative complexity of the model, since obtaining the displacement is an iterative process. The models developed by McLain (1975) and Wang (2009) both utilize the asymptotic model. The asymptotic model was chosen in the study by Wang (2009) because the shape fits the loaddeflection behavior well near the ultimate load. The author placed great importance on this characteristic since the goal was to improve on the existing models, which did not properly predict deflection near ultimate load. It is noteworthy to mention that all the aforementioned models were developed for joints with wood based sheathing and connected to lumber framing using nails. The power model is adopted by several codes and used in design because of its relative simplicity, while being accurate at low and moderate load levels. McCutcheon (1985) stated that this model results in a sufficient description of the slip response because the behaviour of the shear walls up to design load levels is of primary concern and therefore attempting to predict deflections ultimate strength is less important. Model inputs could be obtained through experimental lateral joint tests. Joint level load-deflection equations were obtained based on curve fitting of the experimental data (McCutcheon 1985). Equations for GWB and plywood sheathed joints were developed, however these were only applicable to nails joints. Furthermore, the use of the models were limited to material used in the testing project and could therefore not be generalized.

All of the present model types are viable options and have been proven to be effective for predicting the load-deflection response of a laterally loaded lumber joint. These models are the power model (NDS 2012; CSA, 2014, William and McCutcheon 1985), the exponential model 
(Mack1966; Foschi 1974) and the asymptotic model (McLain 1975; Wang 2009). The model equations are presented in Equation 2, 3 and 4, respectively.

$x=\left(\frac{y}{1000}\right)^{B}$

$y=\left[p_{1}-k_{1} x\right]\left[1-e^{\left(-k_{o} x / p_{1}\right)}\right]$

$y=C-D E^{x}$ or $x=\left(\log \left(\frac{C-y}{D}\right)\right) / \log (E)$

Where $x(\mathrm{~mm})$ is the fastener slip, $y$ is the applied load on the individual fastener $(\mathrm{N}), A$ and $B$ are constants used for the power model curve fitting, C, D and E are constants used for asymptotic model curve fitting, $\mathrm{k}_{\mathrm{o}}$ is the initial tangent stiffness, $\mathrm{k}_{1}$ is the final tangent stiffness and $\mathrm{p}_{1}$ is the intercept of $\mathrm{k}_{1}$ on the load axis.

Although all three models (exponential, asymptotic and power models) were evaluated as part of the current research study to develop the GWB slip model, the power model was selected as the most suitable option. This is mainly due to its simplicity while remaining as accurate as the other models, in addition to its consistency with current models in the timber design standards (NDS 2012; CSA 2014). The exponential model was deemed too complex for a design standard equations since it is an iterative process to determine the fastener slip at a given load. The asymptotic model was also deemed less desirable as a design standard equation model due to its relative complexity compared to the power model and its tendency to underestimate the deflection for the tested GWB sheathed joints. More details on all three slip models can be found in (Lafontaine 2015).

The overarching objective of the current research is to improve the existing nail joint model and to develop a model to estimate the stiffness characteristics of GWB-to-lumber framing screw joints for the purpose of better understanding the behaviour of GWB sheathed shear walls used in light-frame wood structures. 


\section{EXPERIMENTAL PROGRAM}

\section{Material}

The scope of this paper is limited to products representative of those deemed acceptable by regulatory authorities in Canada or the USA and are therefore manufactured in accordance with recognized standards. It should be noted that some products are manufactured or imported and used in construction, however they may not adhere to recognized North American standards as stated in this section, and are therefore outside the scope of the current study. Type-X GWB panels with a thickness of 5/8" (15.9mm) and conforming to ASTM C1396/C1396M (ASTM 2013b) were used in this study. "Regular" GWB was also considered to represent construction details found in light frame wood structures conforming to prescriptive design provisions (NRC 2015; IBC 2009) since the type-X panels are not commonly used for this type of application. "Regular" GWB here refers to any GWB panel that is sold as finishing material that does not carry the Type-X designation, yet conforms to ASTM 1396 (ASTM 2013a). The "regular" GWB used in the study had a thickness of $1 / 2$ " $(12.7 \mathrm{~mm})$. The selection of thickness for each GWB type was based on their commercial material availability. Both light- and normal-weight type-X panels, with weights per unit area of $9.3 \mathrm{~kg} / \mathrm{m}^{2}$ and $11 \mathrm{~kg} / \mathrm{m}^{2}$, respectively, were considered. The “regular" type panels had a weight per unit area of $6.7 \mathrm{~kg} / \mathrm{m}^{2}$.

The lumber material consisted of 2in x 6in $(38 \times 140 \mathrm{~mm})$ No. 2 grade Spruce-Pine-Fir (S-P-F). The full size lumber members were first sorted based on their specific gravity into "high" and "low" density groups with respective average oven dry specific gravity of 0.42 (COV: 5.6\%) and 0.34 (COV: 6.9\%). The density test was conducted according to test method A of ASTM D2395 (ASTM 2007a). The moisture content test was performed in conformance with ASTM D4442 
(ASTM 2007b) and an average moisture content of all tested lumber members was $12.4 \%$ with a COV of $20.3 \%$.

Screws used in this study were \#6, \#8 and \#10 type W screws with a coarse thread shaft and a pointed end with a number 2 bugle head. All tested screws were manufactured according to the ASTM C1002 requirements (ASTM 2013b). In this paper the manufacturers are only assigned designations such as "manufacturer A", since the purpose of the study is to show trends and account for variability in the manufacturing process, which can be done without the need to identify the manufacturer.

Using nails as fasteners for gypsum wallboard application is not as common as screws, however, they are part of the study since GWB nails still have some limited use in practice, and they are the only type of connectors available for GWB joints in the timber design standard (CSA O86 2014). The standard nail for GWB application has a large flat head, a ringed shaft and a long diamond point to reduce cracking in the sheathing (ASTM 2009). Bending tests were performed on the fasteners to determine their yield strength. The average bending strength of $645 \mathrm{MPa}, 750$ $\mathrm{MPa}$ and $585 \mathrm{MPa}$ was found for No.6 screws, No.8 screws and 12.5 gauge nails, respectively.

\section{Experimental setup}

Experimental investigation of the GWB-to-lumber joint behaviour in isolation as well as part of the shear wall was undertaken. A total of 270 joint level tests were conducted including the investigation of three GWB manufacturers, two GWB types, two GWB thicknesses, three nail manufacturers, four screw manufacturers, three screw sizes and two wood density ranges. Each configuration was replicated 10 times. The number of replicates was based on requirements in ASTM D2915 (ASTM 2010) and was also consistent with previous similar study (e.g. Wang 2009). The test matrix for the joint level tests can be seen in Table 1. 
The test specimens consisted of two 8in (203 mm) long, 2in by 6in (38mm x 140mm) wood pieces with GWB sheathing fastened with screws or nails on both sides. Figure 1 shows a schematic of a typical joint level test specimen. One of the lumber pieces contained the test joint while the other was considered to be the dummy end. The fasteners were placed 2 in $(50.8 \mathrm{~mm})$ from the end of the sheathing, to ensure that shearing end distance failure did not occur. The GWB sheathing was cut into 4 in $(101.6 \mathrm{~mm})$ wide and $10.5 \mathrm{in}(266.7 \mathrm{~mm})$ long sections. The dummy end had three screws placed on each side to reduce the slip at that end during testing. It is important to note that the joint displacement was measured between the GWB panel and the lumber piece at the test end, as shown in Figure 2. This means that even if some slip did take place at the dummy end, it would not affect the result at the test end. The fasteners were driven into the lumber according to the method presented in ASTM D1761 (ASTM 2012). The nails at the test end were driven using a standard hammer and the screws were fastened using a screw driver. Both fastener types were driven in such a way that the head was flush with the GWB sheathing and perpendicular to the fastening surface. The joint tests were first performed using a monotonic displacement protocol to obtain the maximum displacement, which formed the basis to develop the reversed cyclic loading protocol, in accordance with ASTM E2126 (ASTM 2011). A total of five $8 \mathrm{ft} \times 8 \mathrm{ft}(2440 \times 2440 \mathrm{~mm})$ wall configurations were constructed with stud grade Spruce-Pine-Fir (SPF) 2x4" (38x89mm) sheathed with 5/8" (15.9 mm) type-X GWB as a wall panel and tested as part of the current research study to validate the developed joint model. The GWB panels were fastened to the wall framing members with either 12.5 gauge nails or \#6 screws. All material used in the construction of the full-scale wall specimens were a subset of the material used in the joint level tests. The studs were connected to the top and bottom plates using two 3.5" 16d smooth shank common nails. Commercially available Simpson Strong-Tie 
proprietary products (HD3B) were used as hold-downs at each end of the walls. A picture of the test setup is shown in Figure 3. One wall fastened with nails and another fastened with screws were subjected to monotonic test protocol to obtain the maximum wall displacement. The maximum displacement is then used as part of the ISO 16670 (ASTM 2011) reversed cyclic displacement protocol to test the rest of the walls. More details, including observations on the failure modes of the GWB sheathed full-scale walls can be found in (Lafontaine,2015).

The parameters studied during the shear walls testing were fastener type, and fastener spacing at panel edges. The fasteners' end and edge distance met the minimum spacing requirement of 9 mm (3/8"), in accordance with the design standard (CSA 2014). Wall-1 and Wall-2 specimens were tested using the monotonic loading protocol in order to obtain the necessary deflection data to perform the reversed cyclic loading protocol. Wall-5 fastener spacing at panel edges is below the recommended $100 \mathrm{~mm}$ spacing by the Canadian design standard (CSA 2014). The spacing was selected in order to determine the effects of attempting to achieve a higher capacity shear wall. Table 2 lists the wall test matrix.

\section{EXPERIMENTAL RESULTS AND DISCUSSION}

\section{Selection of test protocol}

Several studies in the literature have found that the test protocol (monotonic vs. cyclic) has little effect on the behavior of nail or screw joints in light frame wood shear walls where the sheathing consisted of OSB or plywood panels (e.g. Olivia (1990); Dolan et. al. (2003); Sedears et al. (2009)). Although it is not widely established whether the test protocol has any effect on the joint behavior when GWB panel is used, some studies have suggested that the response of GWB sheathed shear walls may be affected by the choice of displacement protocol (Toothman 2003; Seaders et al. 2009). In the current study, the monotonic protocol tests were used to determine 
the ultimate deflection of the specimens, which in turn was used to develop the reversed cyclic loading protocol. Figure 4 presents the comparison between two groups for the joint as well as the full scale tests with identical construction details and with the testing protocol being the only variable. The joint level tests used for the comparison are from the JS-1 and JS-3 replicates and the full scale tests used for the comparison are Wall-1 and Wall-3. For both the joint level and the full scale tests it can be observed that the test protocol seems to have a significant effect on the load-displacement response of the specimen. The initial responses are fairly similar but once peak load is approached, the two responses significantly differ, with the monotonic loading regime yielding higher ultimate strength and higher ductility. Since the cyclic protocol is more representative of seismic loading it was deemed more appropriate to use the cyclic test protocol for all subsequent tests. Whether the results can are applicable in the case of wind loading especially at higher levels of loads may require additional research.

\section{Observed behavior of the joint level tests}

From the joint level tests it was observed that the factors contributing to the fastener slip consisted of crushing in the GWB panel, crushing in the wood member (to a much lesser degree), and yielding of the steel connector. The load-deflection behaviour of all tested joints was consistent and involved the characteristic pinching behavior, strength and stiffness degradation. A typical load-displacement curve is shown in Figure 5 for joint JS-5 (the results from the $7^{\text {th }}$ replicate joint test is shown).

The load-displacement curves for the envelope curves of the ten replicates of the joint level hysteresis are shown in Figure 6 for joint test JS-5. The figure shows reasonable consistency in the results and reflects the variability found in the material used. An average curve for each joint specimen is then used to obtain the backbone curves using the ASTM E2126 standard (ASTM 
2011), which uses the Equivalent Energy Elastic-Plastic (EEEP) Bilinear Model. This model represents an idealized elastic-plastic curve circumscribing an area equal to the area enclosed by the envelop curve between the origin, the ultimate displacement and the displacement axis. The initial stiffness is based on the slope of the line connecting $(0,0)$ and the point on the loaddeflection response corresponding to $40 \%$ of the peak load. This slope intersects with a horizontal line connecting the yield load and the point of $80 \%$ of peak load. The EEEP curve is used as a tool to compare the initial elastic stiffness $\left(\mathrm{k}_{\mathrm{e}}\right)$, yield load $\left(\mathrm{P}_{\mathrm{y}}\right)$ and the ductility ratio $\left(\Delta \mathrm{u} / \Delta_{\text {yield }}\right)$. The EEEP results for all analyzed tests are shown in Table 3 . The analysis was performed on each test group and the average is given with the coefficient of variation in brackets. The coefficient of variation obtained for the tests are within the same range as a coefficient of variation expected for wood based sheathing fastener slip tests (Wang 2009). The joint specimen groups start at JS-5 since JS-1 to JS-4 groups were used to determine the effect of loading types (cyclic and monotonic).

The EEEP analysis parameters were evaluated for each set of tests in order to determine which parameters affected the joint response sufficiently enough to consider them as same or different groups. The tests were grouped based on similar sheathing and fastener type and size, as shown in Table 4. The results for the groups chosen were subjected to a t-test analysis. The t-test compares the mean value and variance of all data sets, using the confidence level of $95 \%$. The results of the analysis confirmed that the parameters which affect the load-deflection response are: fastener size, fastener type, GWB weight per unit area and GWB type. These parameters are taken into account for the development of the fastener slip equation. A curve fitting analysis was then undertaken for each group of joint tests. The least squared method was used to approximate 
the load-slip behavior of the fastener joints. For more details on the analysis results for each group, refer to the thesis work of the first author (Lafontaine 2015).

The slip of an individual joint connecting a GWB panel to a lumber member for screw and nail joints, is expressed in Equations 5 and 6, respectively. The joint equations are developed for type-X 5/8" GWB $\left(9.3 \mathrm{~kg} / \mathrm{m}^{2} \leq \gamma_{G W B} \leq 11.0 \mathrm{~kg} / \mathrm{m}^{2}\right)$ fastened with No.6, No.8, No.10 screws or 12.5 gauge nails.

$e_{n}=\left(4.92-0.42 \gamma_{G W B}\right)\left(\frac{0.016 v_{f}}{d_{s}^{1.33}}\right)^{5.5}$

$e_{n}=\left(2.64-0.18 \gamma_{G W B}\right)\left(0.0037 v_{f}\right)^{3.0}$

where, $e_{n}$ is the fastener deformation $(\mathrm{mm}), \gamma_{G W B}$ is the weight per area $\left(\mathrm{kg} / \mathrm{m}^{2}\right)$ of the Type-X $\mathrm{GWB}, d_{s}$ is the diameter of screw $(\mathrm{mm})$, and $v_{f}$ is the load per fastener $(\mathrm{N})$.

Since only one nail diameter was available for testing, Equation 6 is not a function of the fastener diameter. The current database could be augmented in the future and the expression could be improved if tests of other nail diameters are conducted. This has been identified as a potential future work item.

\section{Validation of developed fastener slip models using full scale Shear wall tests}

The response of full-scale shear wall tests was used to validate the accuracy of the fastener slip models. The full scale shear wall specimens were constructed using the same materials and specifications at the joint level. Equation (1) is used to obtain the static deflection at the top of the shear wall segment with wood-based panels used as sheathing (CSA 2014). 
The fastener slip equations derived from the joint specimen tests for GWB were used to replace the $e_{n}$ value in Equation 1. The goal is to investigate whether including the slip model developed in this study into the deflection equation would yield reasonable results in predicting the wall deflection.

The following input parameters in Equation 1 were the same for all tested full scale shear walls:

- Shear wall height $\left(\mathrm{H}_{\mathrm{s}}\right)$ is $2440 \mathrm{~mm}$

- An average shear-through-rigidity $\left(\mathrm{B}_{\mathrm{v}}\right)$ was found to be $8958 \mathrm{~N} / \mathrm{mm}$. $B_{v}$ was obtained from tests following the ASTM D2719 (ASTM 2013c). The modulus of rigidity was obtained by testing the sheathing. The product of the modulus of rigidity and the thickness of the sheathing is the $\mathrm{B}_{\mathrm{v}}$ value.

- An average modulus of elasticity of the studs (E) was found to be $9000 \mathrm{MPa}$

- The cross-section area of the end studs (A) is $3382 \mathrm{~mm}^{2}$,

- The length of the shear wall $\left(\mathrm{L}_{\mathrm{w}}\right)$ is $2440 \mathrm{~mm}$

- And finally the elongation of the anchorage $\left(\Delta_{\mathrm{a}}\right)$ was assumed to be $0.445 \times 10^{-3} \mathrm{~mm} / \mathrm{N}$. The value for the anchorage elongation was calculated using proprietary engineering data obtained from the manufacturer.

The differences between the configurations are the fastener type and spacing at panel edges. Walls 3 and 4 consisted of $150 \mathrm{~mm}$ panel edge spacing, while the fastener spacing for Wall 5 was $50 \mathrm{~mm}$. The Wall 5 is constructed using a spacing of $50 \mathrm{~mm}$ in order to determine the potential failure modes of a closer fastener spacing while attempting to achieve a substantially higher capacity. Walls 3 and 5 consisted of \#6 screws, while the fastener used in Wall 4 was 12.5 gauge nails. 
The following comparisons are made using the same shear wall deflection equation proposed by the CSA-O86 but utilizing equations 5 and 6 , which both take into account the material variability inherent to the different manufacturers. Figure 7 a-c presents the load-deflection predictions compared to test data obtained from the shear wall tests for walls 3, 4 and 5 , respectively.

It can be seen from Figures $7 \mathrm{a}$ and $7 \mathrm{~b}$ that the predictive models seem to be able to replicate the wall behaviour with reasonable accuracy until peak load. From a design point of view the fit may even be considered to be better. A design level load would be approximately $50 \%$ of the actual peak strength obtained from the test (e.g. wall-3 and Wall-4, the calculated design capacity is 5 $\mathrm{kN}$, compared to ultimate capacity of approx. $11 \mathrm{kN}$ and $8 \mathrm{kN}$ respectively) and as such loads between zero and design level (50\% of peak load), the fit can be considered to be adequate. The model prediction of Wall-5 is less accurate. This result was expected since the small fastener spacing violates the minimum spacing requirements in the design standard (CSA 2014) and caused a brittle failure. The model obviously lacks the ability at this fastener spacing to predict the behaviour observed during the test. The results presented here show that it is feasible to predict the shear wall behaviour based on joint tests, as long as the failure mode observed in the full scale tests are consistent with failure in the joints. If the failure mode changes (in this case to a more brittle failure mode), relying on joint level behaviour to predict the overall wall behaviour becomes no longer valid. It is therefore important to limit the fastener spacing of the model to what is currently allowed in the design standard. It should be noted however that although the model is not accurate at high load levels, the initial portions of all three model predictions follow the load-deflection response reasonably well. The power model accurately describes the response up to $5.4 \mathrm{~mm}$ (approximately $40 \%$ of tested specimen peak load). 
Although outside the scope of the this paper, it should be noted that the applicability of using the joint level capacity to predict the capacity of the full-scale shear wall was demonstrated by comparing the peak load of the shear wall to the peak load obtained from the joint level capacity multiplied by the number of fasteners at the edge of the shear wall. The results showed a good agreement between the test and calculated values. Excluding the Wall-5 configuration, the average error was $4.5 \%$ with a maximum error of $13.2 \%$. For the Wall-5 configuration, which had a fastener spacing of $50 \mathrm{~mm}$ at the panel edges and a brittle failure mode, as expected a large difference between the predicted and test values was found. This further emphasizes the need to limit the fastener spacing or to take the reduced capacity into account if such an approach is implemented in the design standard.

\section{CONCLUSIONS}

As part of this study, 270 GWB sheathed joints and five wall tests were undertaken to develop fastener slip equations for GWB sheathed joints fastened with either nails or screws. The slip models were validated using full-scale GWB sheathed shear walls. The conclusions from this study are as follows:

1) The construction parameters which affect the load-deflection response of GWB sheathed joints were identified as GWB density, fastener size, and fastener type.

2) The power model was found to be a suitable to describe the fastener slip behaviour. A combination of accuracy and simplicity is obtained with the power model equation, which is suitable to develop design equations.

3) The GWB sheathed shear wall deflection could be calculated using the timber design standard deflection equation when the fastener slip component is replaced by the appropriate model proposed in the current study. 
The load-deflection response using the proposed equation did not represent the brittle failure mode observed for the shear walls with fastener spacing of $50 \mathrm{~mm}$ at the panel edge. The minimum panel edge fastener spacing of $100 \mathrm{~mm}$ specified by the Canadian design standard (CSA 2014) should be upheld when using the proposed equations 


\section{REFERNCES}

American Forest \& Paper Association, Inc., 2012. National Design Specifications (NDS) for Wood Construction with Commentary and Supplement: Design Values for Wood Construction 2012 Edition.

ASTM. 2007a. Standard Test Methods for Specific Gravity of Wood and Wood-Based Materials, ASTM D2395, American Society for Testing and Materials. West Conshohocken, PA, US.

ASTM. 2007b. Standard Test Methods for Direct Moisture Content Measurement of Wood and Wood-Based Materials, ASTM D4442, American Society for Testing and Materials. West Conshohocken, PA, US.

ASTM. 2009. Standard Specification for Nails for the Application of Gypsum Board. ASTM C514-04, American Society for Testing and Materials. West Conshohocken, PA, US.

ASTM. 2010. Standard Practice for Sampling and Data-Analysis for Structural Wood and Wood-

Based Products. ASTM D2915-10, American Society for Testing and Materials. West Conshohocken, PA, US.

ASTM. 2011. Standard Test Methods for Cyclic (Reversed) Load Test for Shear Resistance of Vertical Elements of the Lateral Force Resisting Systems for Buildings. ASTM E2126-11, American Society for Testing and Materials. West Conshohocken, PA, US.

ASTM. 2012. Standard Test Methods for Mechanical Fasteners in Wood. ASTM D1761-12, American Society for Testing and Materials. West Conshohocken, PA, US.

ASTM. 2013b. Standard Specification for Gypsum Board. ASTM C1396/C1396M-13, American Society for Testing and Materials. West Conshohocken, PA, US.

ASTM. 2013b. Standard Specification for Steel Self-Piercing Tapping Screws for the Application of Gypsum Panel Products or Metal Plaster Bases to Wood Studs or Steel Studs. 
ASTM C1002, American Society for Testing and Materials. West Conshohocken, PA, US. ASTM 2013c. Standard Test Methods for Structural Panels in Shear Through-the-Thickness. ASTM D2719, American Society for Testing and Materials. West Conshohocken, PA, US.

Canadian Standard Association. 2014. CSA O86-14 Engineering Design in Wood. Mississauga, Canada.

Dolan, J. D., Carradine, D. M., Bott, J. W., and Easterling, W. S., 2003. Design methodology of diaphragms, CUREE W-27, Consortium of Universities for Research in Earthquake Engineering, Richmond, CA.

Foschi, R. O., 1974. Load-Slip Characteristics of Nailed Joints, Journal of Wood Science, vol. 7 , No. 1, pp. 69-76.

Foschi, R. O., and Bonac, T., 1977. Load-Slip Characteristics for Connections with Common Nails, Journal of Wood Science, vol. 9, No. 3, pp. 118-123.

IBC 2015 International Building Code (IBC®), the International Code Council (ICC)

Lafontaine, A., 2015, Investigating the capacity and stiffness of joints used in Gypsum wallboard sheathed light frame wood shear walls, Master of applied science thesis, Ottawa.

Mack, J. J. The strength and stiffness of nailed joints under short duration loading. Technical Report No. 40, Australia Division of Forest Products, CSIRO, Melbourne, Australia, 1966.

McCutcheon, B., 1985. Racking Deformations in Wood Shear Walls, Journal of Structural Engineering, vol. 111 no. 2, pp. 257-269.

McLain, T. E. 1975. "Curvilinear load-slip relations in laterally-loaded nailed joints (Doctoral dissertation, Colorado State University). 
NRC. 2015. National Building Code of Canada. National Research Council of Canada. Ottawa, Canada

Oliva, Michael G., 1990. Racking Behavior of Wood-Framed Gypsum Panels under Dynamic Load, Report No. UCB/EERC-85/06, Earthquake Engineering Research Center, University of California, Berkeley.

Seaders, P., Gupta, R., and Miller, T. H., 2009. Monotonic and Cyclic Load Testing of Partially and Fully Anchored Wood-Frame Shear Walls, Wood and Fiber Science, vol. 41, No.2, pp. 146156.

Toothman, A. J., 2003. Monotonic and Cyclic Performance of Light-Frame Shear Walls with Various Sheathing Materials, M.Sc. Thesis, Virginia Polytechnic Institute, Blacksburg, VA, US.

Wang, Q. Relationship between fastening properties and load-deflection response of wood shear walls, MScFE thesis. University of New Brunswick, Fredericton, NB, 2009. 
List of captions

Figure 1: Typical Joint Level Test Setup

Figure 2: Joint Level Test Setup

Figure 3: Full Scale Test Setup

Figure 4: Full Scale Protocol Comparison for the a) joint level tests and b) full scale tests
a) Joint level tests
b) Full scale tests

Figure 5: Typical Joint Level Hysteresis

Figure 6: Typical Joint Level Average Envelope

Figure 7: Comparison between prediction and test results for wall 3, 4 and 5
a) Wall 3
b) Wall 4
c) Wall 5 
Table 1: Joint Specimen Test Matrix

\begin{tabular}{|c|c|c|c|c|c|c|c|c|}
\hline $\begin{array}{c}\text { JS } \\
\text { Group }\end{array}$ & $\begin{array}{c}\text { GWB } \\
\text { Manu. }\end{array}$ & $\begin{array}{l}\text { GWB } \\
\text { Thick. }\end{array}$ & GWB Type & $\begin{array}{c}\text { Fastener } \\
\text { Manu. }\end{array}$ & $\begin{array}{c}\text { Fastener } \\
\text { Type }\end{array}$ & $\begin{array}{c}\text { Fastener } \\
\text { Size }\end{array}$ & $\begin{array}{c}\text { Wood } \\
\text { Density } \\
\text { Range }\end{array}$ & Loading \\
\hline JS-1 & A & $5 / 8^{\prime \prime}(15.9 \mathrm{~mm})$ & $\mathrm{X}(\mathrm{L} . \mathrm{W})^{1}$ & $\mathrm{~A}$ & Screw & $\# 6(3.80 \mathrm{~mm})$ & High & Monotonic \\
\hline JS-2 & A & $5 / 8 "(15.9 \mathrm{~mm})$ & X (L.W) & A & Nail & 12.5 gauge & High & Monotonic \\
\hline JS-3 & A & $5 / 8 "(15.9 \mathrm{~mm})$ & X (L.W) & A & Screw & $\# 6(3.80 \mathrm{~mm})$ & High & Cyclical \\
\hline JS-4 & $\mathrm{A}$ & $5 / 8 "(15.9 \mathrm{~mm})$ & $\mathrm{X}(\mathrm{L} . \mathrm{W})$ & $\mathrm{A}$ & Nail & 12.5 gauge & High & Cyclical \\
\hline JS-5 & $\mathbf{A}$ & $5 / 8 "(15.9 \mathrm{~mm})$ & X (L.W) & $\mathrm{A}$ & Screw & $\# 6(3.80 \mathrm{~mm})$ & High & Cyclical \\
\hline JS-6 & $\mathbf{A}$ & $5 / 8 "(15.9 \mathrm{~mm})$ & $\mathrm{X}(\mathrm{L} . \mathrm{W})$ & $\mathrm{B}$ & Screw & $\# 6(3.80 \mathrm{~mm})$ & High & Cyclical \\
\hline JS-7 & $\mathbf{A}$ & $5 / 8 ”(15.9 \mathrm{~mm})$ & $\mathrm{X}$ (L.W) & $\mathrm{C}$ & Screw & $\# 6(3.80 \mathrm{~mm})$ & High & Cyclical \\
\hline JS-8 & $\mathbf{A}$ & $5 / 8 "(15.9 \mathrm{~mm})$ & X (L.W) & $\mathrm{D}$ & Screw & $\# 6(3.80 \mathrm{~mm})$ & High & Cyclical \\
\hline JS-9 & $\mathbf{A}$ & $5 / 8^{\prime \prime}(15.9 \mathrm{~mm})$ & X (L.W) & $\mathrm{B}$ & Nail & 12.5 gauge & High & Cyclical \\
\hline JS-10 & $\mathbf{A}$ & $5 / 8 "(15.9 \mathrm{~mm})$ & X (L.W) & $\mathrm{D}$ & Nail & 12.5 gauge & High & Cyclical \\
\hline JS-11 & $\mathbf{A}$ & $5 / 8 "(15.9 \mathrm{~mm})$ & X (L.W) & A & Nail & 12.5 gauge & High & Cyclical \\
\hline JS-12 & $\mathbf{C}$ & $5 / 8 "(15.9 \mathrm{~mm})$ & $\mathrm{X}(\mathrm{R} . \mathrm{W})^{2}$ & $\mathrm{~A}$ & Screw & $\# 6(3.80 \mathrm{~mm})$ & High & Cyclical \\
\hline JS-13 & B & $5 / 8 ”(15.9 \mathrm{~mm})$ & X (R.W) & $\mathrm{A}$ & Screw & $\# 6(3.80 \mathrm{~mm})$ & High & Cyclical \\
\hline JS-14 & A & $5 / 8 "(15.9 \mathrm{~mm})$ & X (R.W) & $\mathrm{B}$ & Screw & $\# 6(3.80 \mathrm{~mm})$ & High & Cyclical \\
\hline JS-15 & $\mathbf{A}$ & $5 / 8^{\prime \prime}(15.9 \mathrm{~mm})$ & X (L.W) & $\mathrm{A}$ & Screw & $\# 8(4.31 \mathrm{~mm})$ & High & Cyclical \\
\hline JS-16 & $\mathbf{A}$ & $5 / 8 "(15.9 \mathrm{~mm})$ & X (L.W) & B & Screw & $\# 10(4.69 \mathrm{~mm})$ & High & Cyclical \\
\hline JS-17 & $\mathbf{A}$ & $5 / 8 "(15.9 \mathrm{~mm})$ & X (L.W) & $\mathrm{D}$ & Screw & $\# 6(3.80 \mathrm{~mm})$ & Low & Cyclical \\
\hline JS-18 & $\mathbf{A}$ & $5 / 8 ”(15.9 \mathrm{~mm})$ & $\mathrm{X}(\mathrm{L} . \mathrm{W})$ & $\bar{A}$ & Screw & $\# 6(3.80 \mathrm{~mm})$ & Low & Cyclical \\
\hline JS-19 & $\mathbf{A}$ & $5 / 8 "(15.9 \mathrm{~mm})$ & X (L.W) & $\mathrm{C}$ & Screw & $\# 6$ (3.80mm) & Low & Cyclical \\
\hline JS-20 & $\mathrm{C}$ & $5 / 8 "(15.9 \mathrm{~mm})$ & X (R.W) & $\mathrm{A}$ & Screw & $\# 6(3.80 \mathrm{~mm})$ & Low & Cyclical \\
\hline JS-21 & $\mathbf{A}$ & $5 / 8 "(15.9 \mathrm{~mm})$ & $\mathrm{X}(\mathrm{L} . \mathrm{W})$ & A & Screw & $\# 8(4.31 \mathrm{~mm})$ & Low & Cyclical \\
\hline JS-22 & A & $5 / 8^{\prime \prime}(15.9 \mathrm{~mm})$ & X (L.W) & $\mathrm{B}$ & Screw & $\# 10(4.69 \mathrm{~mm})$ & Low & Cyclical \\
\hline JS-23 & $\mathrm{A}$ & $5 / 8 "(15.9 \mathrm{~mm})$ & X (R.W) & $\mathrm{E}$ & Screw & $\# 6(3.50 \mathrm{~mm})$ & High & Cyclical \\
\hline JS-24 & A & $5 / 8 "(15.9 \mathrm{~mm})$ & X (R.W) & B & Nail & 12.5 gauge & High & Cyclical \\
\hline JS-25 & $\mathbf{A}$ & $12.7 \mathrm{~mm}(1 / 2 ")$ & Regular & B & Screw & $\# 6(3.50 \mathrm{~mm})$ & High & Cyclical \\
\hline JS-26 & $\mathbf{C}$ & $12.7 \mathrm{~mm}$ (1/2”) & Regular & $\mathrm{B}$ & Screw & $\# 6(3.50 \mathrm{~mm})$ & High & Cyclical \\
\hline JS-27 & B & $12.7 \mathrm{~mm}$ (1/2”) & Regular & B & Screw & $\# 6(3.50 \mathrm{~mm})$ & High & Cyclical \\
\hline
\end{tabular}

${ }^{1}$ Low weight

${ }^{2}$ Regular weight 
Table 2: Shearwall Test Matrix

\begin{tabular}{lcccccc}
\hline & $\begin{array}{c}\text { Sheathing } \\
\text { Thickness } \\
\text { (GWB) }\end{array}$ & $\begin{array}{c}\text { Fastener } \\
\text { Type }\end{array}$ & $\begin{array}{c}\text { Fastener } \\
\text { Size }\end{array}$ & $\begin{array}{c}\text { Fastener } \\
\text { Spacing at Panel } \\
\text { Edges }\end{array}$ & Loading & $\begin{array}{c}\text { Number of } \\
\text { Replicates }\end{array}$ \\
\hline Wall $-\mathbf{1}$ & $5 / 8 ”(15.9 \mathrm{~mm})$ & Screw & No.6 & $150 \mathrm{~mm}$ & Monotonic & 1 \\
Wall $-\mathbf{2}$ & $5 / 8 ”(15.9 \mathrm{~mm})$ & Nail & 12.5 gauge & $150 \mathrm{~mm}$ & Monotonic & 1 \\
Wall $-\mathbf{3}$ & $5 / 8 ”(15.9 \mathrm{~mm})$ & Screw & No.6 & $150 \mathrm{~mm}$ & Cyclical & 2 \\
\hline Wall $-\mathbf{4}$ & $5 / 8 ”(15.9 \mathrm{~mm})$ & Nail & 12.5 gauge & $150 \mathrm{~mm}$ & Cyclical & 2 \\
Wall $-\mathbf{5}$ & $5 / 8 ”(15.9 \mathrm{~mm})$ & Screw & No.6 & $\mathbf{5 0 ~} \mathbf{~ m m}$ & Cyclical & 2 \\
\hline
\end{tabular}


Table 3: EEEP analysis of the Joint Specimens

\begin{tabular}{|c|c|c|c|c|c|}
\hline JS Group & Peak Load (N) & $\begin{array}{c}\text { Deflection at } \\
\text { Peak Load } \\
(\mathrm{mm})\end{array}$ & $\begin{array}{c}\text { Initial Stiffness } \\
(\mathrm{N} / \mathrm{mm})\end{array}$ & Yield Load (N) & $\begin{array}{c}\text { Ductility Ratio } \\
\left(\Delta \mathbf{u} / \Delta_{\text {yield }}\right)\end{array}$ \\
\hline JS-5 & $500.9(6.28 \%)$ & $4.7(7.07 \%)$ & $738.2(29.5 \%)$ & $446.8(5.74 \%)$ & $13.9(24.6 \%)$ \\
\hline JS-6 & $539.5(4.32 \%)$ & $4.4(3.76 \%)$ & $1280.7(24.3 \%)$ & $489.7(5.07 \%)$ & $25.6(27.5 \%)$ \\
\hline JS-7 & $500.0(6.20 \%)$ & $4.51(3.32 \%)$ & $836.7(30.2 \%)$ & $436.7(6.82 \%)$ & $14.7(26.1 \%)$ \\
\hline JS-8 & $516.5(8.73 \%)$ & $4.4(2.60 \%)$ & $868.2(48.0 \%)$ & $455.9(6.15 \%)$ & $14.6(37.2 \%)$ \\
\hline JS-9 & $409.0(7.75 \%)$ & $4.9(14.96 \%)$ & $262.8(27.2 \%)$ & $364.2(6.32 \%)$ & $7.0(20.9 \%)$ \\
\hline JS-10 & $449.4(8.30 \%)$ & $4.6(4.34 \%)$ & $437.3(38.5 \%)$ & $398.0(7.3 \%)$ & $9.0(39.3 \%)$ \\
\hline JS-11 & $494.1(5.16 \%)$ & $4.4(6.44 \%)$ & $819.7(62.8 \%)$ & $437.2(6.58 \%)$ & $17.7(70.3 \%)$ \\
\hline JS-12 & $592.3(6.22 \%)$ & $4.4(5.62 \%)$ & $1497.0(25.2 \%)$ & $532.8(5.62 \%)$ & $23.4(25.0 \%)$ \\
\hline JS-13 & $621.6(7.47 \%)$ & $4.5(2.79 \%)$ & $1569.8(26.5 \%)$ & $561.30(7.65 \%)$ & $26.9(25.9 \%)$ \\
\hline JS-14 & $755.5(3.85 \%)$ & $4.3(9.88 \%)$ & $2129.4(38.3 \%)$ & $678.2(4.43 \%)$ & $24.0(33.8 \%)$ \\
\hline JS-15 & $576.1(6.35 \%)$ & $4.2(13.4 \%)$ & $953.7(31.82 \%)$ & $530.3(5.65 \%)$ & $15.6(34.7 \%)$ \\
\hline JS-16 & $539.1(4.83 \%)$ & $4.7(13.5 \%)$ & $1042.9(39.28 \%)$ & $493.0(4.69 \%)$ & $21.2(36.9 \%)$ \\
\hline JS-17 & $504.7(4.09 \%)$ & $4.4(10.8 \%)$ & $1247.3(43.04 \%)$ & $461.6(4.56 \%)$ & $22.4(38.8 \%)$ \\
\hline JS-18 & $663.7(5.33 \%)$ & $16.3(31.0 \%)$ & $2009.3(52.0 \%)$ & $663.7(5.33 \%)$ & $125.7(53.9 \%)$ \\
\hline JS-19 & $797.1(2.54 \%)$ & $14.2(3.85 \%)$ & $2983.8(55.2 \%)$ & $754.4(6.97 \%)$ & $84.0(62.9 \%)$ \\
\hline JS-20 & $537.1(9.14 \%)$ & $4.5(6.80 \%)$ & $1273.0(33.4 \%)$ & $482.8(9.58 \%)$ & $24.4(29.4 \%)$ \\
\hline JS-21 & $490.2(4.91 \%)$ & $4.4(4.12 \%)$ & $967.2(39.3 \%)$ & $442.9(5.37 \%)$ & $21.7(40.3 \%)$ \\
\hline JS-22 & $644.6(7.87 \%)$ & $4.3(8.00 \%)$ & $1536.1(29.8 \%)$ & $575.8(6.44 \%)$ & $24.9(34.4 \%)$ \\
\hline JS-23 & $661.6(5.39 \%)$ & $4.2(7.69 \%)$ & $1458.2(32.5 \%)$ & $591.7(5.98 \%)$ & $24.9(28.0 \%)$ \\
\hline JS-24 & $501.3(6.29 \%)$ & $4.6(2.39 \%)$ & $367.2(42.1 \%)$ & $446.2(4.90 \%)$ & $7.8(37.6 \%)$ \\
\hline JS-25 & $472.8(6.24 \%)$ & $4.4(3.94 \%)$ & $1045.1(25.4 \%)$ & $434.2(6.36 \%)$ & $19.8(33.3 \%)$ \\
\hline JS-26 & $523.8(5.58 \%)$ & $4.3(4.47 \%)$ & $1772.4(30.2 \%)$ & $472.2(5.28 \%)$ & $27.8(31.7 \%)$ \\
\hline JS-27 & $538.4(6.15 \%)$ & $4.5(7.9 \%)$ & $1804.1(17.1 \%)$ & $485.8(6.32 \%)$ & $30.5(26.9 \%)$ \\
\hline
\end{tabular}


Table 4: Parameter Influence Groups

\begin{tabular}{cccc}
\hline Group & GWB Type & $\begin{array}{c}\text { Fastener } \\
\text { Diameter }\end{array}$ & JS Group \\
\hline $\mathbf{1}$ & L.W. $^{1}-\mathrm{X}\left(5 / 8^{\prime \prime}\right)$ & No. 6 & JS-5, JS-6, JS-7, JS-8, JS-17, JS-18, JS-19 \\
$\mathbf{2}$ & R.W. $^{2}-$ X $\left(5 / 8^{\prime \prime}\right)$ & No. 6 & JS-12, JS-13 JS-20, JS-23, JS-14 \\
$\mathbf{3}$ & L.W. - X $\left(5 / 8^{\prime \prime}\right)$ & No. 8 & JS-15, JS-21 \\
$\mathbf{4}$ & L.W. - X (5/8”) & No. 10 & JS-22, JS-16 \\
$\mathbf{5}$ & Regular GWB (1/2”) & No. 6 & JS-25, JS-26, JS-27 \\
$\mathbf{6}$ & L.W. - X (5/8”) & Nails -12.5 gauge & JS-9, JS-10, JS-11 \\
\hline${ }^{1}$ Low weight & & & \\
${ }^{2}$ Regular weight & & &
\end{tabular}




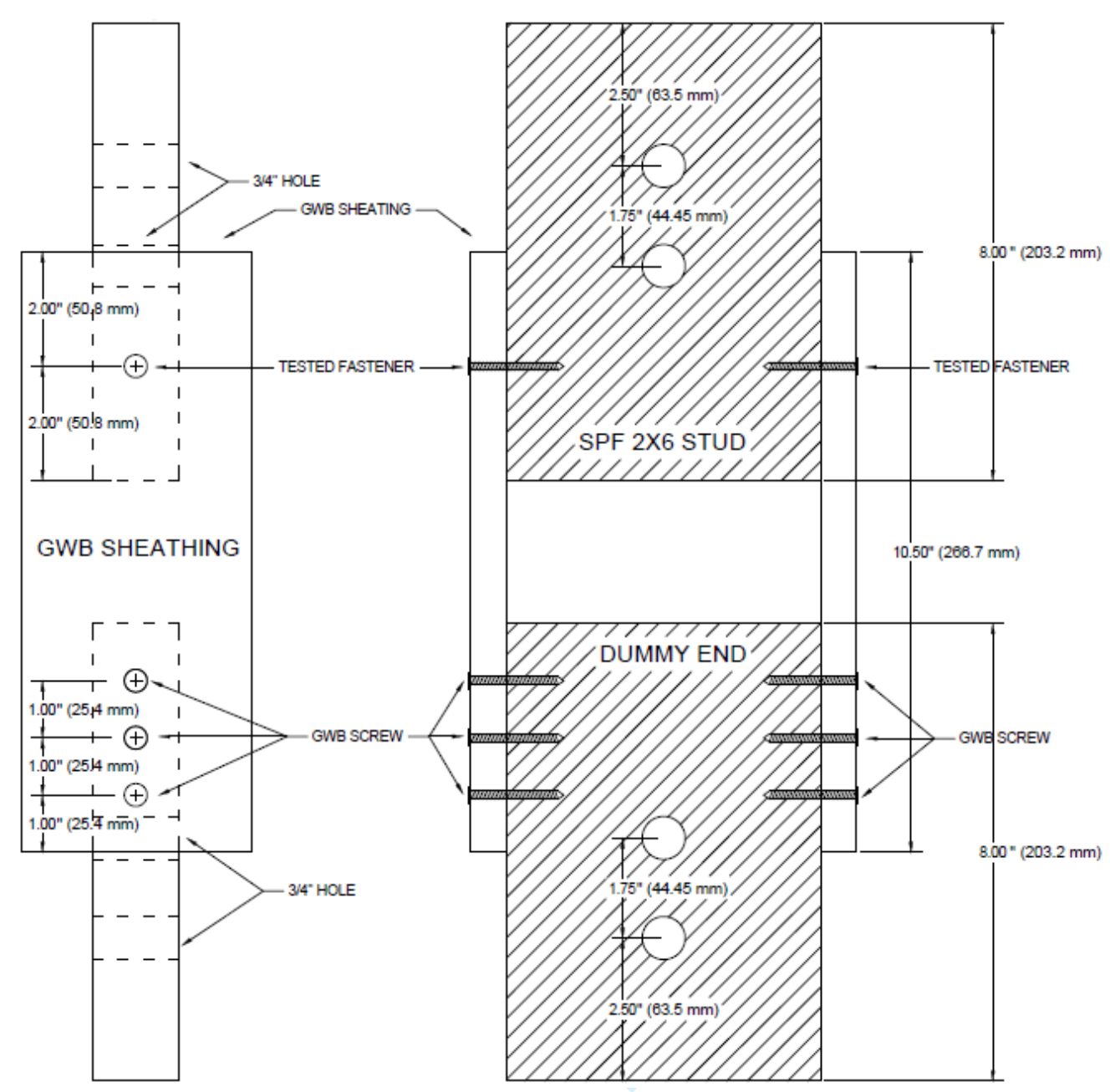



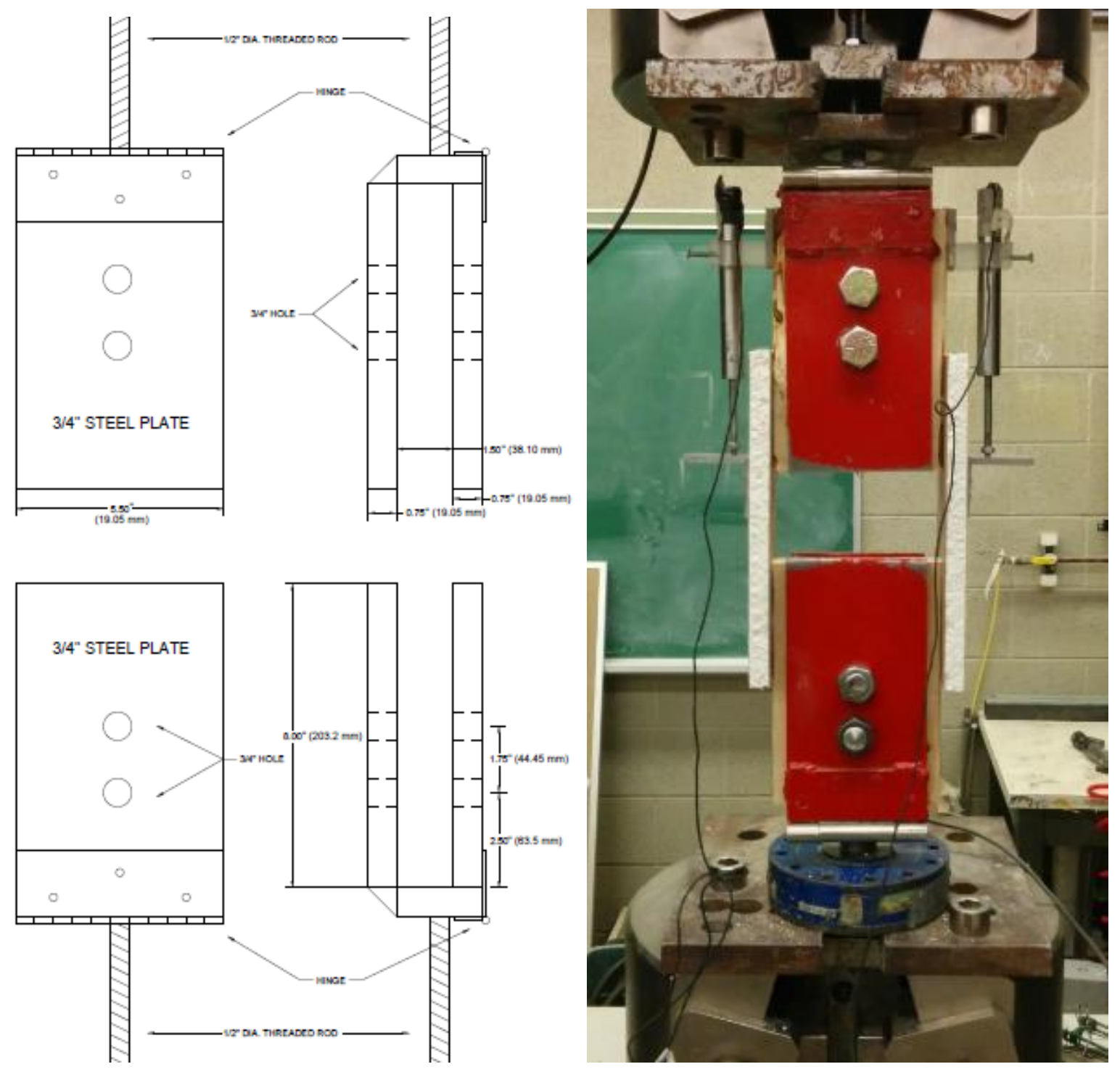


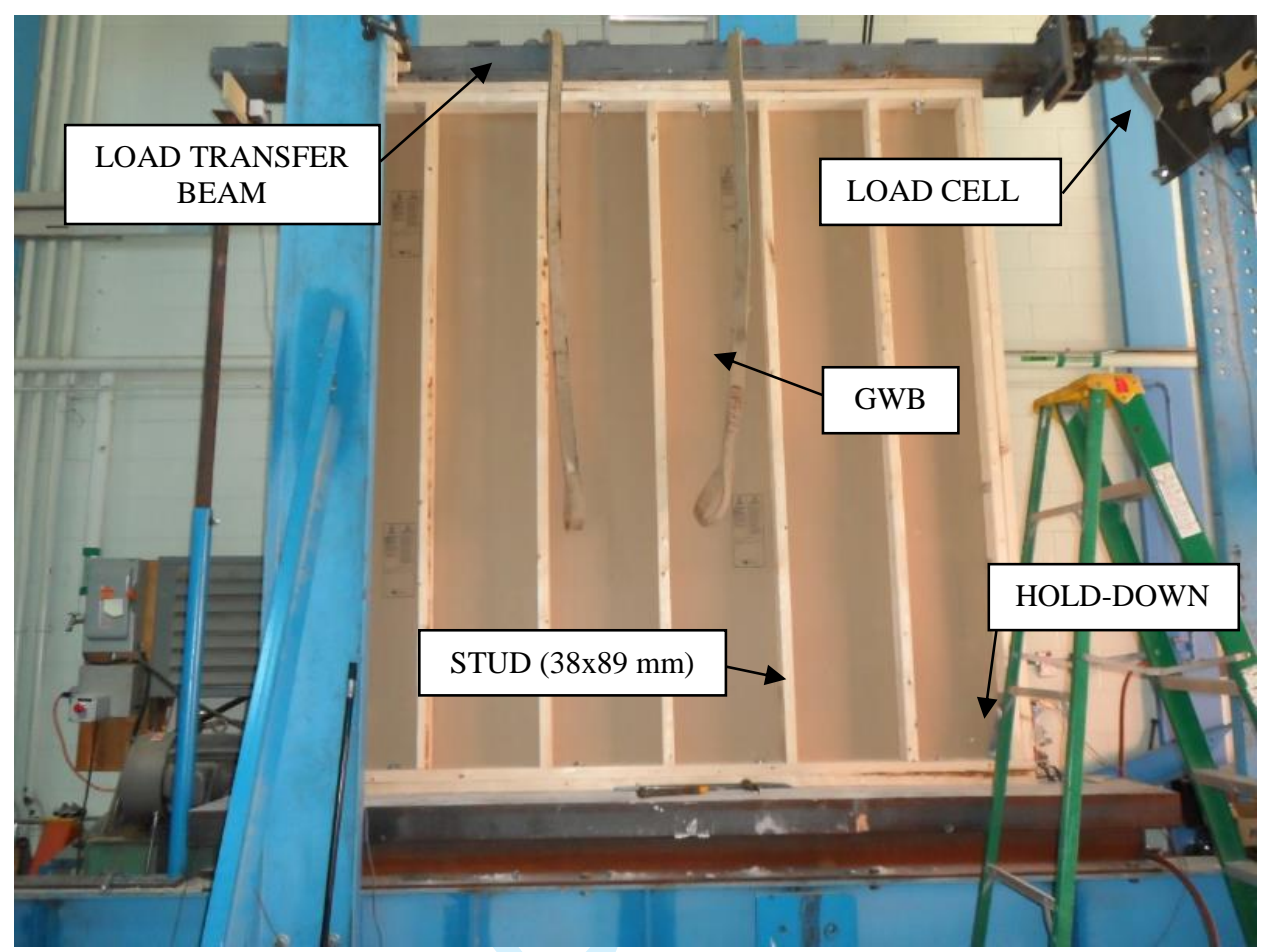

https://mc06.manuscriptcentral.com/cjce-pubs 


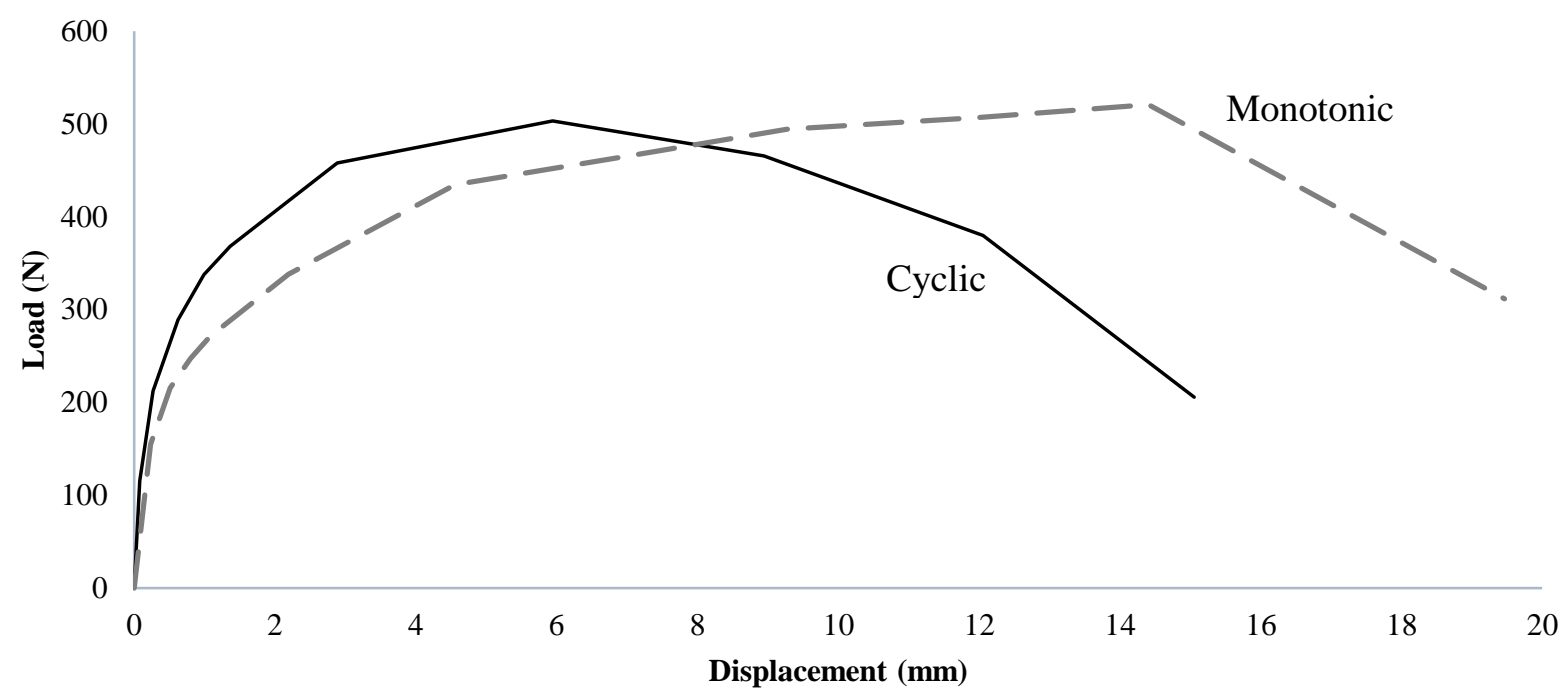

a) Joint level tests

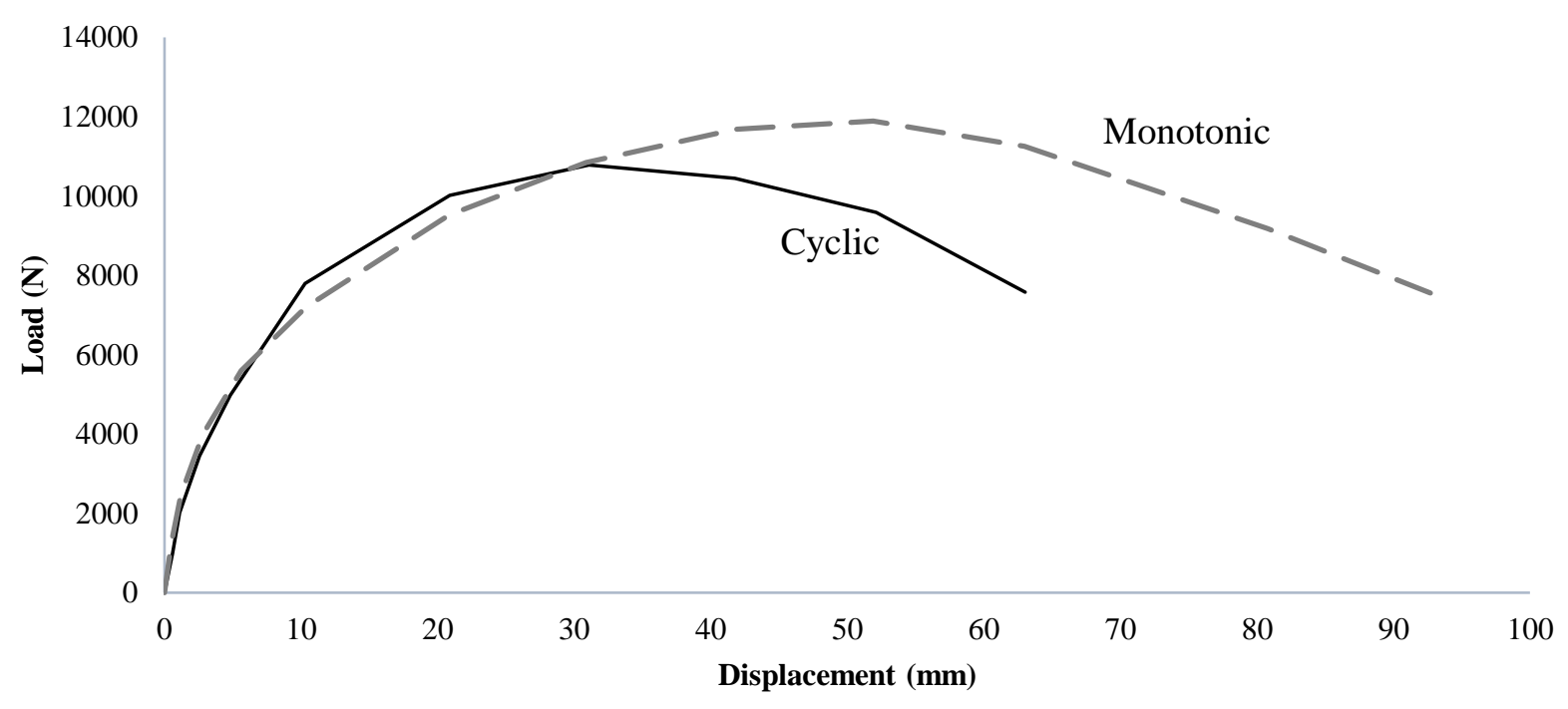

b) Full scale tests 


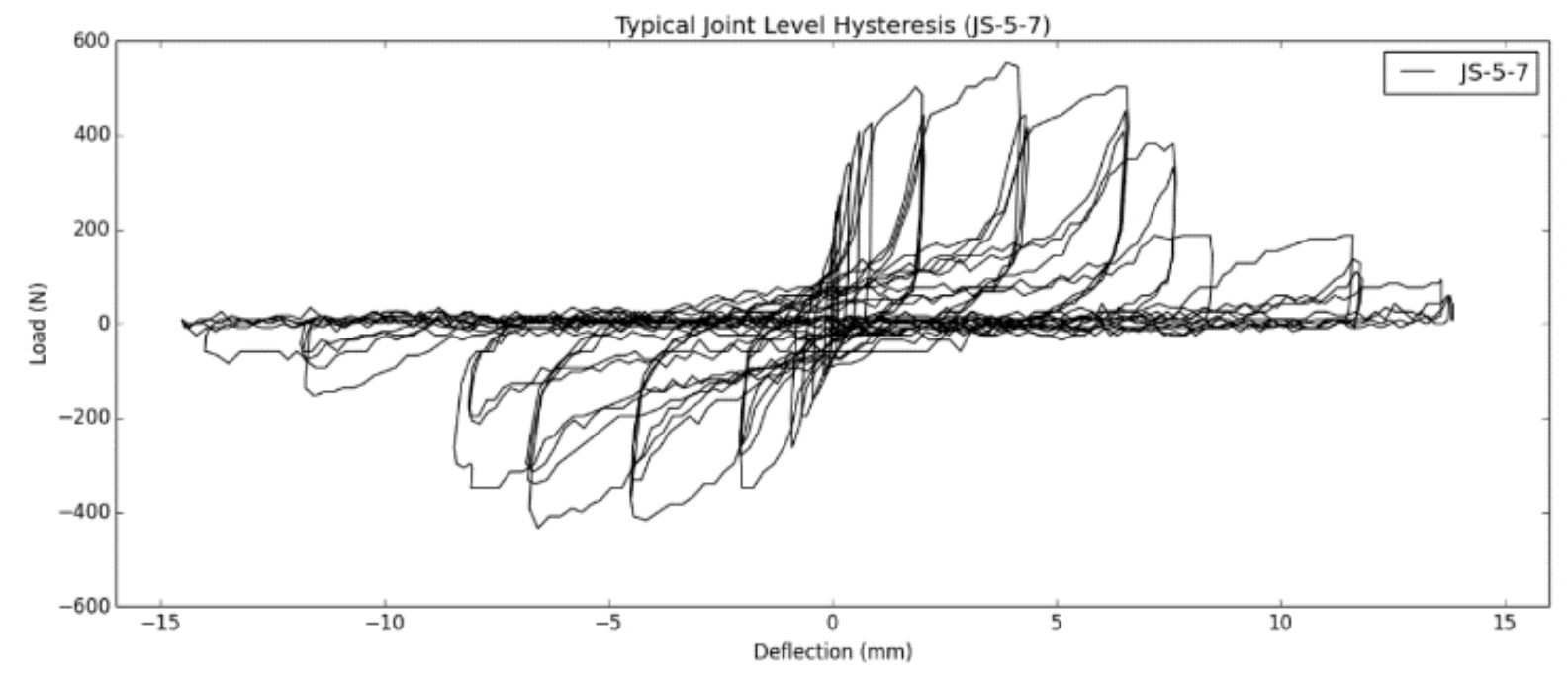

https://mc06.manuscriptcentral.com/cjce-pubs 


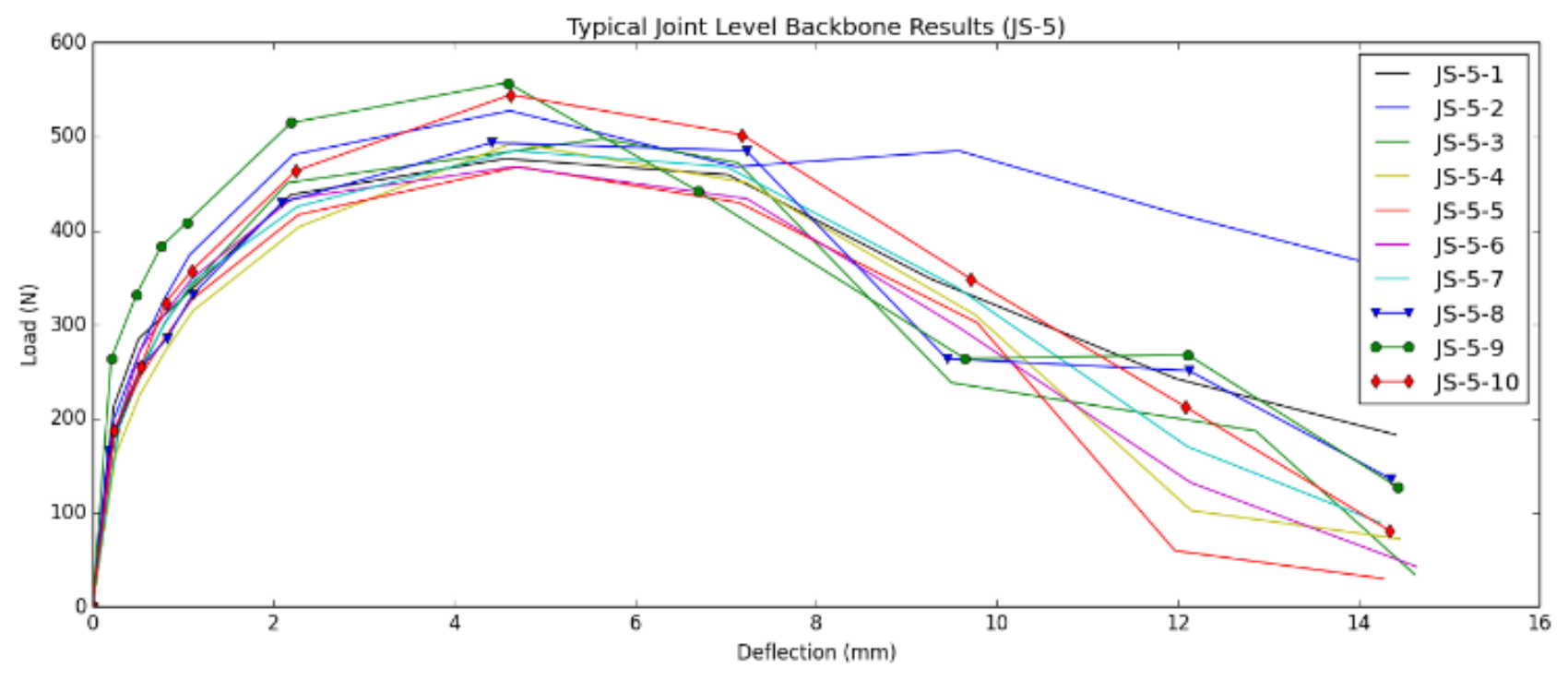




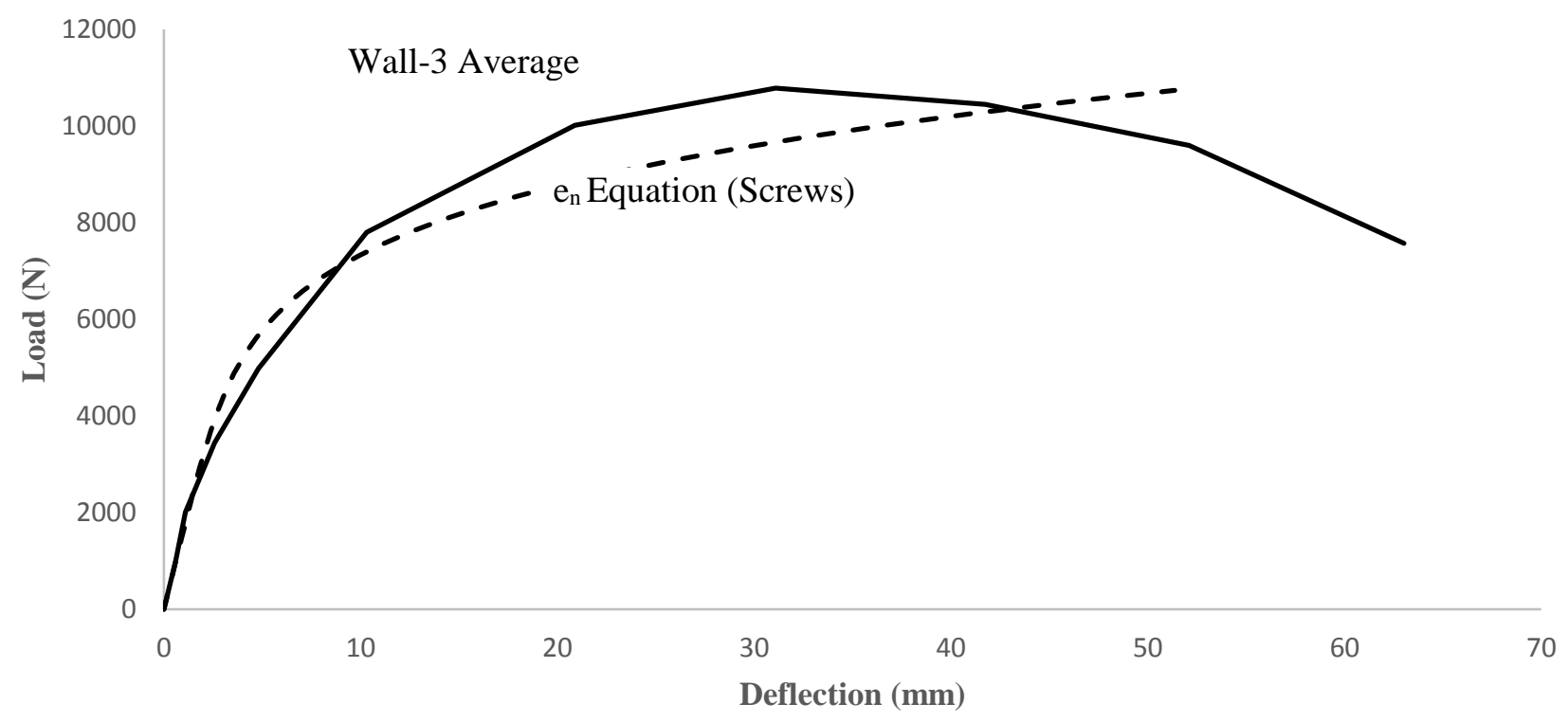

(A) Wall 3

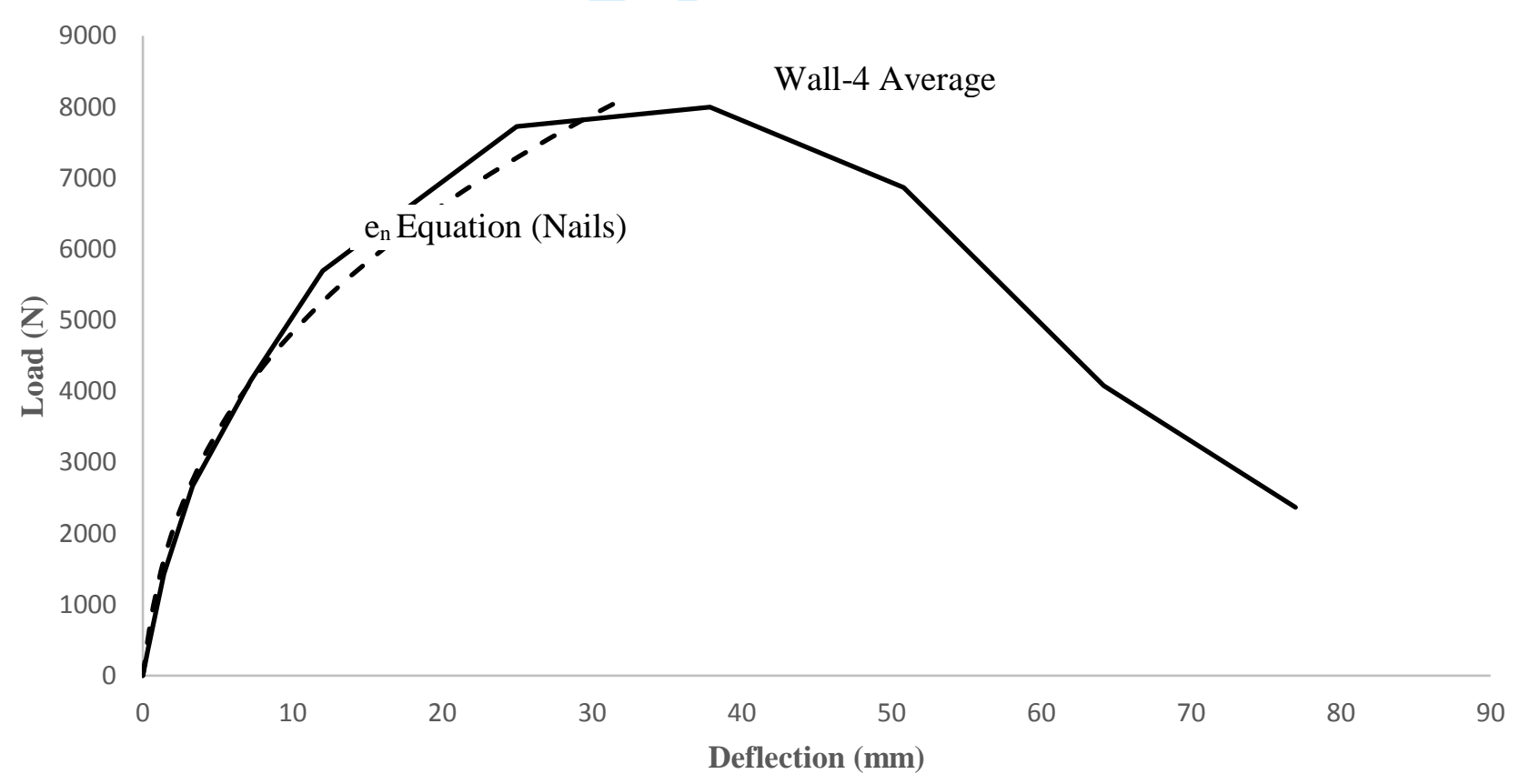

(B) Wall 4 


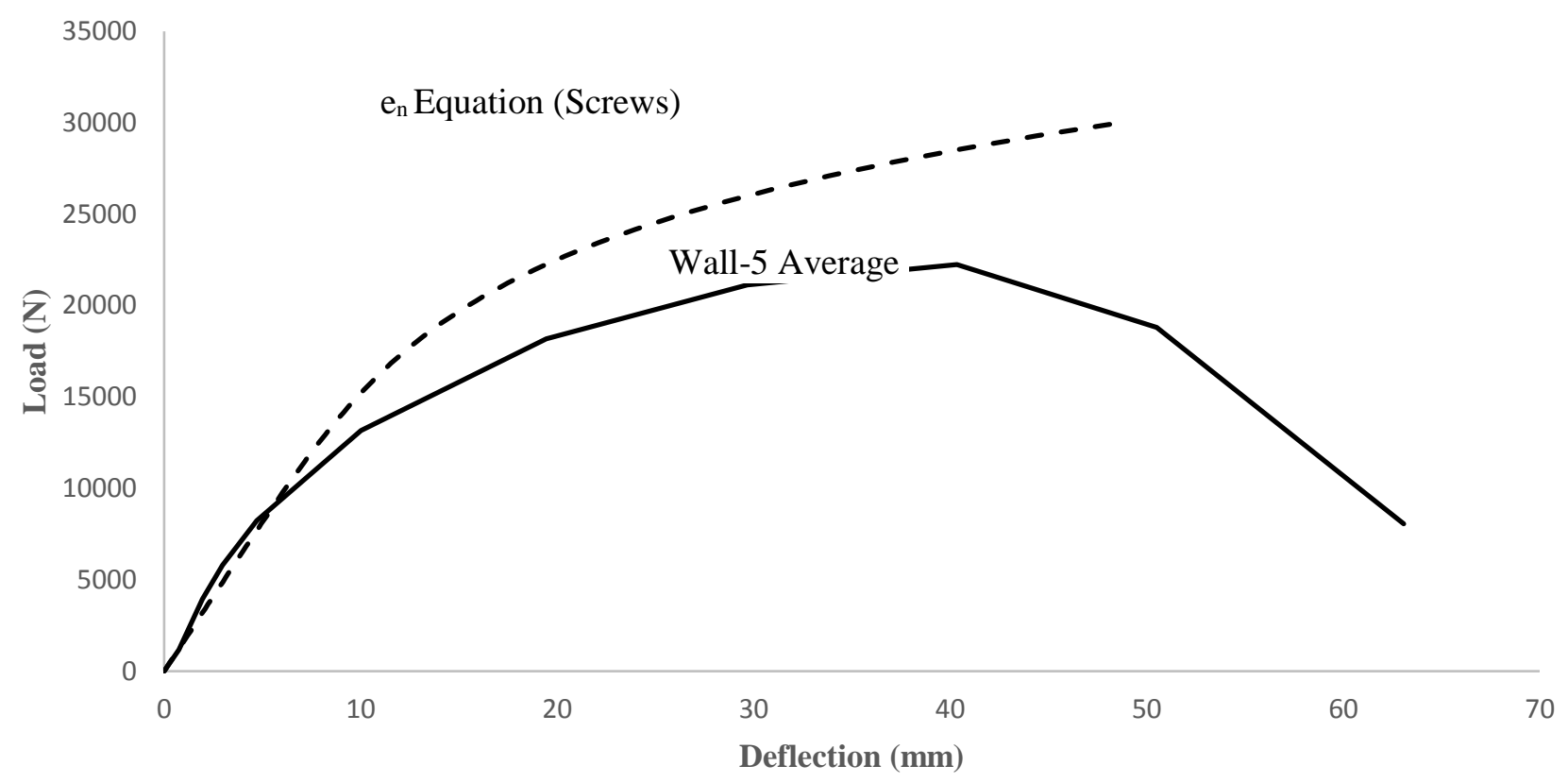

(C) Wall 5 